\title{
Somente financiamento importa? Possíveis fatores associados à escolha de modos de oferta de creche
}

\section{Does financing matter? Possible factors associated with the choice of daycare provision modes}

\author{
Zara Figueiredo Tripodi ${ }^{1}$ \\ Erisvaldo Pereira dos Santos ${ }^{2}$ \\ Marco Antônio Torres ${ }^{3}$
}

\begin{abstract}
Resumo: O artigo examina, a partir de resultados de pesquisa, a constituição do tecido do Estado brasileiro, no âmbito da interação público e privado, na oferta de creche, buscando compreender as lógicas de expansão do acesso explicitadas nos Planos Municipais de Educação formulados e/ou reformulados em 2015, por determinação do art. $8^{\circ}$ da Lei $\mathrm{n}^{\circ}$ 13.005/2014, que institui o Plano Nacional de Educação para a década de 2014-2024. Discute-se, ainda, a partir de uma amostra estatística de 169 municípios, os possíveis fatores explicativos de escolhas expressas pelos documentos decenais, no que tange a essa etapa educacional.
\end{abstract}

Palavras - chave: Política Educacional; Educação Infantil; Governança

Educacional.

\begin{abstract}
The article examines, based on research results, the constitution of the fabric of the Brazilian State, within the scope of public and private interaction, in the provision of day care, seeking to understand the logics of expanding access explained in the Municipal Education Plans formulated and / or reformulated in 2015, as determined by art. 8 of Law No. 13,005 / 2014, which institutes the National Education Plan for the decade 2014-2024. It is also discussed, from a statistical sample of 169 municipalities, the possible explanatory factors of choices expressed by the ten-year documents, with respect to this educational stage.
\end{abstract}

Keywords: Educational Policy; Child education; Educational Governance.

\section{Introdução}

Um número considerável de pesquisas que se dedicam à temática das políticas educacionais da primeira infância tem trazido evidências de que a expansão da oferta de creche no país tem se efetivado, em larga medida, por meio da interação entre Estado e

\footnotetext{
1 Zara Figueiredo Tripodi, Doutora em Educação pela USP, Prof ${ }^{a}$. do Departamento de Educação e do Programa de Pós-Graduação em Educação da UFOP, Ouro Preto, Minas Gerais, Brasil. zarafigueiredo@ufop.edu.com

2 Erisvaldo Pereira dos Santos, Doutor em Educação pela UFMG, Prof. do Departamento de Educação e do Programa de Pós-Graduação em Educação da UFOP, Ouro Preto, Minas Gerais. Brasil. erisvaldosanto@yahoo.com.br

3 Marco Antônio Torres, Doutor em Psicologia pela UFMG, Prof. do Departamento de Educação e Programa de Pós-Graduação em Educação da UFOP, Ouro Preto, Minas Gerais. Brasil. torresgerais@gmail.com
}

Revista Devir Educação, Lavras, vol.4, n.2, p.431-444 jul./dez., 2020. 
Organizações da Sociedade Civil -OSC's. Alguns trabalhos reconhecem, inclusive, que a própria capacidade estatal, no âmbito das creches, tem sido também produzida em decorrência dessa relação socioestatal. (CAMPOS, 2006).

Tendo, pois, como pano de fundo esses arranjos interacionais, já reconhecidos pela literatura da área (CAMPOS, 1997; CAMPOS, 2006; CECCOM, DRABACH, 2020), objetivou-se, com o trabalho, primeiro, investigar como os municípios brasileiros, constrangidos normativamente pelas leis locais que aprovaram os Planos Municipais de Educação, em 2015, expressaram em seus marcos legais, os modos de oferta que seriam utilizados de modo a alcançar a meta $01 \mathrm{~B}$ do PNE, que previa, no indicador 2, o aumento de até $50 \%$ de vagas de creche, tendo em vista a demanda manifesta. E, articulada a essa questão, soma-se a segunda, que foi indagar se apenas a variável "financiamento", ou seja, os recursos financeiros eram os únicos fatores explicativos de um cenário que já vinha se delineando, historicamente, que é expansão de vagas de creche por meio de arranjos socioestatais.

Isso porque não se pode deixar de considerar que, de um lado, o valor mínimo alunoano, para a fase de creche é subponderado, haja vista o limitado número de crianças-turma e que se pode ter em uma creche, o que implica em significativo esforço orçamentário do município para atender à demanda. De outro lado, cabe reconhecer que a oferta de matrículas de creche constitui-se como um importante ativo político, que tende a levar a população a recompensar eleitoralmente os mandatários do cargo quando promovem a expansão do sistema.

Ainda que a presença de atores privados, especialmente os que constituem o denominado terceiro setor, fizeram-se presentes na oferta de vagas, de modo mais específico, na esfera da creche, o exame mais detido da composição do Estado brasileiro, em termos de políticas públicas, permite afirmar que ele sempre foi permeável a lógicas privatizantes.

A porosidade do Estado a lógicas, instrumentos e interesses privados, em maior ou menor extensão, estiveram presentes ao longo da construção do Estado nacional, e já fora documentado em diferentes perspectivas teórico-analíticas. Do trabalho clássico de Sérgio Buarque de Holanda (1976) às discussões sobre permeabilidade estatal desenvolvidas por Marques (2000), a constatação de que, no país, as fronteiras entre público e privado apresentam, historicamente, um forte padrão de porosidade, esteve presente nas análises de Fernando Henrique Cardoso (1971), ao examinar o "planejamento do Brasil”; na investigação de Leal ( 1969), sobre o coronelismo nos municípios brasileiros e, nos anos de 1980, no 
trabalho de Nunes (1987) sobre as "Gramáticas políticas do Brasil - clientelismo, corporativismos e insulamento burocrático".

Ainda que a delimitação precisa do privado demande uma discussão que enfeixe tanto vertentes sociológicas, políticas, quanto econômicas, para fins desse trabalho, toma-se como "privado", o grupo de instituições de propriedade e direito privado, com ou sem fins lucrativos; sendo que nesta última categoria, encontram-se as entidades localizadas no chamado Terceiro Setor, que atuam na área de serviços de corte social, também denominadas Organizações da Sociedade Civil - OSC's, com formatos jurídicos diversos.

Tendo em conta essa definição assumida, é possível afirmar, baseado nas evidências acumuladas por pesquisas da área (ADRIÃO, 2008; PERONI, 2008; TRIPODI e SOUSA, 2018; TRIPODI, DELGADO e CASTILHO, 2018) que se convive, nas políticas de educação brasileira, com diferentes modulações do privado na esfera pública. No que tange à oferta educacional, conforme já anunciado, a interação entre público e privado tem sido mais sistemática na educação infantil, em creches, embora iniciativas dessa ordem comecem a se fazer conhecer em etapas como ensino fundamental e médio.

Pesquisas como a de Campos, Coelho e Cruz (2006) afirmam que a presença do privado, especialmente instituições filantrópicas e assistenciais, na creche, não apenas foi sistemática, ao longo dos tempos, como também contribuiu para a própria expansão do campo, em que pese os problemas relativos à qualidade da oferta.

Se a presença de instituições privadas contribuiu para melhorar os índices de acesso da criança pequena à creche, o atendimento à totalidade da demanda manifesta encontra-se bem abaixo do desejado e formulado na Meta 1 B, do Plano Nacional de Educação (PNE) para a década 2014-2024, aprovado pela Lei n 13.005/2014. Segundo o Relatório do $2^{\circ}$ Ciclo de 2018, elaborado pelo Instituto Nacional de Estudos e Pesquisas Educacionais Anísio Teixeira - INEP, o país alcançou $39.1 \%$ de uma meta de 50\% de atendimento até 2024. Deve-se considerar, ainda, que essa média nacional "camufla" índices regionais muito menos expressivos, como do Amazonas ou Alagoas, por exemplo, em que o percentual alcança $12.8 \%$ e $25.4 \%$, respectivamente.

O Plano Nacional de Educação (2014-2024), em que pese o veto ao art. 21, da Lei de Diretrizes Orçamentárias para 2018, que tratava de priorizar o orçamento necessário para se cumprir suas metas, ainda representa significativo avanço para o campo educacional, do ponto de vista do planejamento e da política pública de educação. Isso porque, em comparação a 
outros planejamentos decenais já construídos pelo país, esse buscou constituir-se em expressão de política de Estado, não de governo, exibindo uma ancoragem democrática mais robusta, o que reverberou, por isso mesmo, nas diretrizes, que alicerçam e sustentam o PNE. Ademais, o documento decenal buscou definir e preencher as lacunas deixadas pela Lei de Diretrizes e Bases da Educação Nacional (LDBEN), Lei n 9.394, de 1996, no tocante à gestão democrática, dando-lhe contornos mais definidos.

No que tange à engenharia institucional federativa, o PNE também apresenta um significativo avanço na medida exata que redefine o papel da União em termos de financiamento da educação, com a introdução do Custo Aluno Qualidade Inicial - CAQi e a sua lógica redistributiva a partir da complementação financeira da União aos estados e municípios. Embora a implementação do CAQi, como originalmente delineada no PNE, não fora aprovada, a instituição da Emenda Constitucional $n^{\circ}$ 108/2020, que aprova o novo Fundeb, de caráter permanente, e garante o princípio da qualidade pode ser considerado um grande avanço. Ademais, a regulamentação do novo fundo prevê a destinação de $50 \%$ dos $10,5 \%$ da complementação da União, à educação infantil, no âmbito do Valor Aluno Ano Total - VAAT.

De todo modo, o PNE também trouxe, necessariamente, no texto legal e no seu anexo, 20 metas ambiciosas que contam, cada uma, com um conjunto de estratégias de modo a alcançá-las, sendo a educação infantil a primeira delas. No "corpo" da meta 01, o texto explicita a dimensão do desafio posto aos municípios: universalizar a educação infantil, na fase pré-escolar, até 2016; e garantir que, até 2024, 50\% das crianças de 0 a 3 anos de idade tenham acesso à creche.

À publicação da Lei $n^{\circ} 13.005 / 2014$, seguiu-se outra, um mês depois, intimamente vinculado à oferta de creche no Brasil, que foi a Lei $n^{\circ}$ 13.019/2014, conhecida como Marco Regulatório do Terceiro Setor - MROSC.

Tendo em vista esse cenário, delineado pela aprovação do PNE e pelas possibilidades de superação dos impasses do financiamento educacional por ele trazidas; pelas metas arrojadas estipuladas para a educação infantil, especialmente, na fase creche, e, por fim, pela regulamentação das parcerias entre Estado e terceiro setor, a pesquisa da qual originou o presente trabalho, buscou compreender possíveis fatores explicativos para a composição do tecido estatal, em termos de interação público-privado, de modo a alcançar a Meta 1B, expressa em Planos Municipais de Educação - PME, formulados e/ou reformulados em 2015, 
por determinação do art. $8^{\circ}$ da Lei $n^{\circ} 13.005 / 2014$.

\section{Contornos do privado na Educação}

O debate sobre os arranjos público-privados no campo da educação tem sido realizado por diferentes chaves interpretativas. Para Adrião (2018), é possível delimitá-los, pelo menos, em duas dimensões: a da gestão, na medida em que se transfere as lógicas reguladoras para OSC's ou mesmo para instituições com finalidades de lucro. Já a outra dimensão, refere-se ao currículo, haja vista a penetração de sistema de apostilamento desenvolvido por grupos privados, na esfera pública.

Ao analisar as origens das parcerias público-privadas, Robertson e Verger (2012) afirmam que elas estão presentes em vários países, constituindo-se mesmo um mercado educacional que não representam a diminuição do Estado, mas sua redefinição em termos de funções no campo da educação.

Dale (1994), por sua vez, afirma que o mercado educacional tem como objetivo retirar a responsabilidade e custos do Estado para, teoricamente, melhorar os níveis de eficiência da área educacional.

Ao investigar "a mercantilização da educação", Stephen Ball (2014) argumenta que as políticas educacionais se transformaram em mercadoria, em compra e venda, em negócios, gerando lucro para as empresas privadas, através de contrato com o Estado, na esfera do contexto inglês.

Olhando para o caso brasileiro, Souza e Oliveira (2003) explicam que parece estar se desenvolvendo no Brasil uma lógica de "quase-mercado", fundada na premissa de que a competição promover melhor qualidade dos serviços, embora, na verdade, o que se nota é a produção de resultados desiguais. (SOUSA; OLIVEIRA, 2003).

Já para Tripodi e Sousa (2018), é preciso pensar a permeabilidade do Estado a lógicas privatizantes, no que tange à educação, sob duas perspectivas: de um lado, a assimilação de instrumentos gerenciais, típicos da iniciativa privada, como estrutura de metas incentivos ou mesmo escolha dos pais. De outro, a possibilidade de oferta da educação por instituições da sociedade civil organizada como Organizações Sociais -OS's ou Organizações da Sociedade Civil de Interesse Público - OSCIP's. Nesse caso, as autoras compreendem que a categoria teórica "governança" tem um significativo potencial explicativo de arranjos público-privados. 


\section{DEVIR EDUCAÇÃO}

ISSN: 2526-849X

Embora tenha se tornado bastante atual e até mesmo popular, o termo governança comporta uma ampla gama de definições e, também, de confusões conceituais. Uma das primeiras menções ao termo pode ser encontrada no documento Governance and Development, de 1992, do Banco Mundial o mesmo define governança como "a maneira pela qual o poder é exercido na administração dos recursos econômicos e sociais do país, com vistas ao desenvolvimento" (WORLD BANK, 1992, p. 1).

No campo acadêmico, um dos primeiros autores a tratar do tema da governança foi Rhodes que, há em 1996, afirmava que, de modo geral, governança está relacionada à alteração pela qual a sociedade passa a ser governada. No entanto, o autor reconhece que o termo é polissêmico e, por isso, tem sido utilizados, pelo menos, de conceitualmente, de seis modos distintos: i) estado mínimo, ii) como governança corporativa, iii) como a nova gestão pública, iv "boa governança", v) sistema sócio-cibernético ou vi) como redes autoorganizadas"(RHODES,1996, p.653).

Já Kooiman (2003) define o termo a partir de uma concepção sociopolítica, de modo que a governança pública estaria interligada à premissa de existência de múltiplos atores atuando no processo político, tanto públicos como privados. Para o autor, parece bastante improvável que determinado governo seja capaz de gerir um Estado, de modo unitário, sem atuação de atores societais. Dessa forma, para Kooiman (2003), no que tange às questões governamentais, elas não devem ser apenas públicas ou privadas, devem, antes, serem compartilhadas, indo do nível local ao supranacional e se expandido entre diferentes atores sociais. (KOOIMAN, 2003).

Tendo em vista esse debate proposto por Kooiman (2003), o trabalho assume o conceito de governança dado pelo autor, como a interação de atores situados na esfera do Estado e societais na formulação e oferta de serviços de corte social (KOOIMAN, 1993), de modo a examinar os arranjos expressos pelas municipalidades, nos seus PME's, para a oferta de creche.

\section{Percurso metodológico}

Em termos metodológicos, o desenho da pesquisa, de natureza exploratória, privilegiou a abordagem qualitativa, para mapear as lógicas de oferta de educação infantil explicitadas em 169 Planos Municipais de Educação, e utilizou-se, para isso, de um conjunto 
de procedimentos como: i) pesquisa documental de fontes primárias, ou seja, leis sancionadas por cada ente municipal; ii) pesquisa bibliográfica e teste estatístico para testar hipóteses levantadas; iii) análise de conteúdo, utilizando a técnica de Bardin (2009).

Os PME's foram selecionados a partir de uma amostra estatística estratificada aleatória de municípios, produzida a partir da observação de quatro variáveis: i) Gasto per capita do município; ii) população total do município; iii) PIB per capita e iv) capacidade estatal.

A amostra foi gerada pelo software R, no qual foram submetidas as seguintes bases de dados: i) dados sobre gastos dos municípios das Finanças do Brasil - FINBRA corresponde ao ano de 2012; ii) PIB per capita dos municípios do Instituto Brasileiro de Geografia e Estatística - IBGE correspondente ao ano de 2011; iii) população do município do IBGE, do ano de 2011; iv) capacidade estatal, de Pesquisa de Informações Básicas Municipais MUNIC/IBGE, corresponde a 2014; v) coloração político-ideológica, a partir de dados do Superior Tribunal Eleitoral -STE.

A hipótese com a qual se trabalhou foi a de que os municípios tenderiam a intensificar a governança educacional (KOOIMAN, 1993; RHODES, 1996; DINIZ, 1996; MELO, 1996), na etapa creche, entendida, aqui, como uma dispersão de oferta para atores situados na sociedade civil organizada, com diferentes desenhos e institutos jurídicos, movidos pelo desequilíbrio do federalismo fiscal, expresso no financiamento desta fase, já que à responsabilidade das matrículas da educação infantil pelo ente municipal não correspondeu uma transferência de recursos equivalente por parte da União ou dos estados, pelo constrangimento legal imposto pelas metas da educação infantil do PNE e pelo reconhecimento da oferta de vagas em creche como forma de legitimação de governos municipais.

\section{Resultados e Discussão}

A análise dos PME's e Plano Distrital de Educação permite afirmar, de um lado, que a presença de atores situados na Sociedade Civil está presente, de forma significativa, no tecido do Estado, podendo ser observado em todas as regiões brasileiras, sem haver um nicho geográfico onde ela se concentre; de outro lado, que essa tendência apresenta contornos diferentes entre as municipalidades examinadas. Assim sendo, 73 municípios, de um total de 
169, explicitaram nos seus PME's que a expansão da oferta da educação infantil, na etapa creche, irá se efetivar, de modo a cumprir a meta estipulada pelo PNE, em interação com entidades do chamado terceiro setor, conforme se pode depreender da leitura da Tabela 01.

Tabela 01: Distribuição de oferta da educação infantil por ator estatal e não-estatal, por região. 2015.

\begin{tabular}{|l|l|l|l|l|}
\multicolumn{5}{|c|}{ Brasil } \\
\hline \multirow{2}{*}{ Região } & \multicolumn{1}{|c|}{ Distribuição de oferta da educaço infantil por ator estatal e não-estatal } \\
\cline { 2 - 6 } & $\begin{array}{c}\text { Oferta por meio de interação } \\
\text { com o Terceiro Setor }\end{array}$ & \multicolumn{1}{c|}{ Oferta Estatal } & $\begin{array}{c}\text { Não } \\
\text { informado }\end{array}$ & Total \\
\hline Centro-Oeste & 10 & 10 & 0 & 20 \\
\hline Nordeste & 21 & 27 & 3 & 51 \\
\hline Norte & 9 & 8 & 12 & 17 \\
\hline Sudeste & 18 & 20 & 1 & 50 \\
\hline Sul & 15 & 15 & 16 & 31 \\
\hline Total & 73 & 80 & & 169 \\
\hline & & & 12 & \\
\hline
\end{tabular}

Fonte: Planos Municipais e Distrital de Educação. Elaboração própria

O exame dos PME's permitiu observar uma multiplicidade de atores do terceiro setor com os quais os municípios explicitaram intenção de firmar parcerias. Embora o termo "convênio" ainda seja uma das expressões mais recorrentes nos documentos, em referência às Leis $\mathrm{n}^{\circ}$ 8.666, de 1993, e a Lei $\mathrm{n}^{\circ} 12.101$, de 2009, um conjunto de municípios estabeleceu nos seus documentos que pretende estabelecer parcerias, também, com entidades privadas com fins lucrativos, além de Organizações Sociais- OS's e Organizações da Sociedade Civil de Interesse Público - OSCIP's. Outro aspecto que pode ser verificado é que de 25 capitais e Distrito Federal, apenas quatro municípios não explicitaram, em seus PME's, a intenção de interagir com o terceiro setor na oferta de creche: Boa Vista (RR), Belém (PA), Vitória (ES) e Fortaleza (CE). Situados no polo oposto, estão Belo Horizonte e o Distrito Federal que apresentaram, do ponto de vista documental, uma tendência mais consolidada de a educação infantil se efetivar via terceiro setor. Nesta perspectiva, foi possível verificar que municípios com desenhos institucionais e capacidades estatais muito díspares têm, na interação com o privado, seu ponto de intersecção. Nesse sentido, tem-se, à maneira de ilustração, municípios como Turmalina, localizado no Vale do Jequitinhonha (MG), considerada uma das regiões mais pobres do Brasil, que em seu PME explicitou o propósito de expandir seu sistema via Organizações Sociais - OS's, mas, também, Betim, que possui significativa atividade industrial, bem como significativo padrão fiscal e arrecadatório, fazendo a mesma "opção" do 
município interiorano.

Contudo, há uma diferença no "movimento" que essas tendências fazem no interior de cada município, no sentido da natureza do mecanismo relacional, finalidade da interação e nível de concretização de parceria.

Alguns municípios limitaram-se a mencionar que interagiriam com o "terceiro setor", sem especificar o mecanismo relacional; se as relações se dariam com Organizações SociaisOS's, Organização da Sociedade Civil de Interesse Público - OSCIP's ou outra forma de parceria. Esse é um aspecto importante, pois a natureza desse vínculo pode levar a formatos diferentes de parceria. Firmar convênio com uma OS tem efeitos diferentes que pactuar com uma OSCIP, em termos de privatização da coisa pública. Já o termo "convênio" ou “conveniamento", em referência à Lei n 12.101, de 27 de novembro de 2009, que dispõe sobre a certificação das entidades beneficentes de assistência social, foi o formato jurídico com maior ocorrência nos Planos.

Já a opção de lógica de oferta de matrículas de creche, no caso de São Paulo, pode ser explicada, em larga medida, pela capacidade que atores políticos e/ou sociais têm de influenciar e agir sobre determinada agenda, levando à adoção de determinada medida ou ação, em detrimento de outra. Isso porque o projeto de lei do PME, enviado ao legislativo paulista, em um dos Substitutivos, recebeu redação para a meta relacionada à educação infantil em que se manifestava o objetivo de ampliação da oferta via rede municipal direta:

META 5. Universalizar, até 2016, a Educação Infantil para as crianças de 4 (quatro) a 5 (cinco) anos de idade e ampliar a oferta de Educação Infantil na rede municipal direta de forma a atender toda a demanda efetiva da população de zero até 3 anos e 11 meses no prazo de cinco anos. (SÃO PAULO, 2014).

Tal proposição é reafirmada em seguida, nas estratégias 5.2. e 5.3, nas quais o município trata de especificar a data limite para finalizar o atendimento via parceria com o Terceiro Setor, além de explicitar a intento de incorporar à rede pública as iniciativas privadas:

5.2. Investir em unidades públicas de Educação Infantil diretas, limitando-se o atendimento na rede conveniada, desde que assegurados os padrões de qualidade definidos pelo município, às matrículas realizadas até 2014;

5.3. Realizar processo de reincorporação dos Centros de Educação Infantil indiretos para responsabilidade direta da Secretaria Municipal de Educação, de forma gradativa no prazo de cinco anos; [...]. (SÃO PAULO, 2014).

Entretanto, essa proposta não contou com o apoio político necessário para fazê-lo 
prevalecer, levando a que novo Substitutivo, o de $n^{\circ}$ 02, fosse apresentado e aprovado. Nele, prevalece a ideia de que o sentido de público está mais relacionado à gratuidade do serviço prestado do que ao ator responsável pela oferta, portanto, público não significaria, necessariamente, estatal. A tentativa de reverter a situação foi levar para o Plenário emendas. Contudo, todas elas, no que tange ao modo de oferta somente por ator estatal, foram rejeitadas, levando-se ao seguinte texto final para a meta referente à educação infantil:

\section{Meta 5}

Universalizar, até 2016, a Educação Infantil para as crianças de 4 (quatro) e 5 (cinco) anos de idade e assegurar, durante a vigência do Plano, atendimento para $75 \%$ das crianças de zero a 3 anos e 11 meses ou 100\% da demanda registrada, o que for maior.

\section{Estratégias:}

5.1. Investir na ampliação da oferta de educação infantil de 0 (zero) a 3 (três) anos na rede direta, indireta e conveniada, assegurando sua qualidade. (SÃO PAULO, 2015).

Nota-se que a meta foi alterada, na medida em que é retirada do corpo do texto a menção à "rede municipal direta" e a primeira estratégia (5.1) complementa o novo texto ao expressar que as modalidades em que se pautarão a oferta de creche: direta, indireta e conveniada.

De modo geral, o exame do conjunto de municípios que compuseram a amostra permite afirmar que entes municipais com resultado orçamentário e fiscal muito distintos fizeram opção pela interação público-privado na oferta de creche, levando-se, por isso, à hipótese de que o financiamento educacional não seria a única variável a ser mobilizada para se explicar a escolha expressa pelos PME's. Nesse sentido, o trabalho utilizou testes estatísticas para testar variáveis que ultrapassassem a discussão tributária fiscal e incluíssem outros aspectos como capacidade administrativa e orientação ideológica.

Contudo, os testes estatísticos evidenciaram que as variáveis relativas ao comportamento tributário-fiscal dos municípios como resultado orçamentário, despesa corrente, receita corrente e gasto com educação apresentaram uma diferença significativa no que diz respeito à presença de atores societais no tecido do Estado, em municípios, o que permite afirmar que uma fraca saúde financeira e pouca capacidade de produção de receita influencia positivamente a interação público-privada, levando-se, portanto, à reformulação da hipótese. Os coeficientes associados ao comportamento financeiro municipal mantiveram-se positivos e significantes em todos testes, com exceção das transferências discricionárias 
voluntárias e das transferências provenientes do Fundo de Manutenção e Desenvolvimento da Educação Básica e de Valorização dos Profissionais da Educação - FUNDEB que não mostraram associação significativa. A existência de secretaria exclusiva de educação, entendida como um dos elementos representativos da capacidade administrativa do município, não apresentou significância no modelo utilizado.

A opção por considerar, na modelagem, também, a variável coloração ideológica está alicerçada na literatura recente sobre o tema (MADEIRA e TAROUCO, 2011) que afirma que a discussão entre esquerda, centro e direita precisam ser pensados, na atualidade, não apenas em termos de índice de intervenção do Estado na economia, mas, também, na defesa (ou não) de lógicas privatizantes.

No caso da variável ideologia partidária, tinha-se como hipótese que as municipalidades dirigidas por gestores alinhados à esquerda do espectro político brasileiro tenderiam a escolher lógicas de oferta via Estado e aquelas vinculadas à direita optariam por uma lógica voltada ao terceiro setor. Para medir essa variável e sua possível correlação com escolhas expressas pelos municípios, foi identificado o partido dos prefeitos das capitais, em 2012, e qual a sua ideologia partidária, a partir das estimativas de posicionamento ideológico dos principais partidos brasileiros realizadas por Zucco Jr (2009).

A conclusão do teste mostrou que os municípios cujos prefeitos são de partidos alinhados com a Direita possuem proporção maior de intenção de oferta pelo terceiro setor, 87\%. Enquanto para o caso da Esquerda esse percentual é de $60 \%$. A princípio, a diferença entre as proporções de $60 \%$ e $87 \%$ entre Esquerda e Direita são expressivas, mas cabe lembrar que, do ponto de vista estatístico, o número de capitais não é muito grande, 25 , sendo que não contamos com a informação de duas delas (Cuiabá e Rio de Janeiro). Por conta disso, tem-se a não rejeição da hipótese nula de independência entre as variáveis a um nível de 5\% de significância, o que significa que a ideologia partidária do prefeito não parece estar associada ao modo de oferta dessa etapa educacional.

\section{Conclusões}

A pesquisa trouxe evidências que a "governança" do Estado brasileiro, no que tange à oferta de creche, e no sentido conceitual que lhe dá Kooiman (2003), tem se efetivado por uma forte presença de atores privados, situados na esfera da sociedade civil organizada, conforme explicitado nos PME's para a década 2014-2024. Embora os documentos municipais tenham seguido lógicas distintas de estruturação, um traço comum entre eles é a 
opção pela oferta da primeira etapa da educação infantil em interação com atores societais, efetivando processos de governança educacional. O mapeamento da oferta, via amostra, dá conta de que apenas dois municípios explicitaram a intenção de restringir a interação com a sociedade civil na oferta da Educação Infantil, até 2024, embora o façam atualmente: Belém (PA), Vitória (ES), Fortaleza (CE) e Boa Vista (RR).

Em sentido oposto, alguns municípios explicitaram em seus documentos que tendem a fortalecer a dispersão da oferta para a sociedade civil organizada, por meio de institutos jurídicos distintos como o antigo convênio, mas, também, com Organizações Sociais - OS's. A amostra permitiu observar que há municípios com lógicas de parceria mais consolidadas que outros, expressas em seus planos decenais.

Utilizando o conceito de governança, o trabalho buscou investigar, ainda, possíveis fatores explicativos para a opção de oferta de vagas em creche por atores situados fora do aparelho de Estado. A ferramenta conceitual mostrou-se profícua por permitir captar outras variáveis que pudessem dar conta de explicar os modos de oferta privilegiados, extrapolando o argumento clássico de natureza tributário-fiscal.

Tanto os testes estatísticos realizados, assim como a revisão da literatura empreendida, sugerem que variáveis relacionadas ao comportamento orçamentário dos entes municipais, como resultado fiscal, receitas e despesas correntes, gastos com educação, têm correlação positiva com a escolha pelo modo de oferta via terceiro setor, o que confirma a hipótese clássica relacionada ao financiamento educacional.

Já variáveis voltadas à capacidade estatal, ideologia partidária e FUNDEB não se mostraram significativas para explicar a lógica explicitada nos PME’s.

Por fim, não parece descabido afirmar que esse tecido do Estado, que entrelaça diferentes atores, expressa, por um lado, uma tendência que pode ser observada em todas as regiões e, por outro, que essa lógica de oferta de educação infantil parece se constituir mesmo em política de Estado, tendo em vista, sobretudo, que se encontra expressa em Planos Municipais de Educação para uma década (2014-2024).

Relativamente aos modos de oferta da educação infantil para a década, tudo leva a crer que a expansão do sistema de modo a alcançar as metas do PNE se darão por meio de arranjos diferentes com o terceiro setor, em vários formatos jurídicos, devendo se tornar essa lógica uma "política permanente" de oferta de matrículas em creche (ARELARO, 2008). Embora se possa elucubrar que esse fator se deve, também, à indução da União, haja vista que o próprio 
texto legal do PNE trazia em uma das estratégias, a 1.7, a proposta de articulação de oferta de matrículas gratuitas em creches certificadas como entidades beneficentes de assistência social na área de educação com a expansão da oferta na rede escolar pública, as razões explicativas para essa tendência precisa ser melhor formulada, considerando, principalmente, a dependência de trajetória da educação infantil brasileira, cujas origens remontam à assistência social e à filantropia.

\section{Referências}

ADRIÃO, Theresa; PERONI, Vera (Org.) Público e Privado na Educação. Novos elementos para o debate. São Paulo: Xamã Editora, 2008, pp. 99-110.

ARELARO, L. A não-transparência nas relações público- privadas: o caso das creches conveniadas. In: Theresa Adrião; Vera Peroni. (Org.). Público e Privado na Educação: novos elementos para o debate. 1 ed. São Paulo: Xamã, 2008, v. 1, p. 51-66.

BRASIL. Lei $\mathbf{n}^{\circ} \mathbf{1 3 . 0 0 5}$, de 24 de junho de 2014. Aprova o Plano Nacional de Educação PNE e dá outras providências.

BRASIL. Lei $n^{\circ}$ 13.019, de 31 de julho de 2014. Estabelece o regime jurídico das parcerias voluntárias, envolvendo ou não transferências de recursos financeiros, entre a administração pública e as organizações da sociedade civil, em regime de mútua cooperação, para a consecução de finalidades de interesse público; define diretrizes para a política de fomento e de colaboração com organizações da sociedade civil; institui o termo de colaboração e o termo de fomento; e altera as Leis nos 8.429, de 2 de junho de 1992, e 9.790, de 23 de março de 1999.

CAMPOS, Maria Malta. Educação infantil: o debate e a pesquisa. Cadernos de Pesquisa, 1997.

CAMPOS, Maria Malta; COELHO, Rita de Cássia; CRUZ, Silva Vieira H. Consulta sobre a qualidade da educação infantil. São Paulo: FCC/DPE, 2006. Relatório Final.

CARDOSO, F. H. "Aspectos políticos do planejamento". In. LAFER, Bettly Mindlin. Planejamento no Brasil. São Paulo: Editora Perspectiva, 1975.

CECCON, MARIA LUCIA LEMOS; DRABACH, NADIA PEDROTTI. As instituições sem fins lucrativos na privatização da educação infantil. Educ. rev., Belo Horizonte , v. 36, e231107, 2020

DINIZ, E. Governabilidade, governance e reforma do Estado: considerações sobre o novo paradigma. Revista do Serviço Público. Ano 47, vol. 120, n² 2, Mai-Ago 1996. 
DOURADO, Luiz Fernandes (Org). Plano Nacional de Educação (2011-2020): avaliação e perspectivas. Belo Horizonte: Autêntica; Goiás: UFG, 2011.

KOOIMAN, J. Governing as Governance. Sage. 2003.

MADEIRA, Rafael Machado.; TAROUCO, Gabriela da Silva. Esquerda e direita no Brasil: uma análise conceitual. Revista Pós Ciências Sociais, v.8, n.15, p.171-186, jan-jun. 2011.

MARQUES, E. C. Estado e Redes sociais: permeabilidade e coesão nas políticas urbanas no Rio de Janeiro. Rio de Janeiro: Revan; São Paulo: Fapesp, 2000.

MELO, M. M. Governance e Reforma do Estado: O Paradigma Agente X Principal. Revista do Serviço Público, 1996, ano 47, vol. 120, nº 1, pp. 67-82, jan/abr, 1996.

PERONI, Vera. A relação público/privado e a gestão da educação em tempos de redefinição do papel do Estado. In. ADRIÃO, Theresa; PERONI, Vera (Org.). Público e Privado na Educação: novos elementos para o debate. São Paulo: Xamã Editora, 2008, p. 111-127.

RHODES, R.A.W. The New Governance: Governing without Government. In. Political Studies, XLIV, 1996, p.652-667.

SÃO PAUlO (SP). Proposta de Substitutivo ao PL no 415/2012 - Versão Preliminar. Diário Oficial do Município. São Paulo, 2014.

SÃO PAULO (SP). Lei $\mathbf{n}^{\circ}$ 16.271, de 17 de setembro de 2015. Aprova o Plano Municipal de São Paulo. Diário Oficial do Município. São Paulo, 2015.

TRIPODI, Zara Figueiredo; DELGADO, Victor Maia Senna; RODRIGUES, Érica Castilho. Permeabilidade estatal e atores privados na oferta da educação infantil: o que dizem os Planos Municipais de Educação (2014-2024)? Rev. Bras. Educ., Rio de Janeiro, v. 23, e230064, 2018 .

TRIPODI, Zara Figueiredo; SOUSA, Sandra Zákia. Do governo à governança: permeabilidade do estado a lógicas privatizantes na educação. Cad. Pesqui., São Paulo, v. 48, n. 167, p. 228-253, Mar. 2018.

WORLD BANK. Governance and Development. 1992.

ZUCCO JR, C. Esquerda, direita e governo: a ideologia dos partidos políticos brasileiros. Seminário Legislator Views of Brazilian Governance. Universidade de Oxford, setembro de 2009. p. 1-18.

Recebido em: 14/10/2020

Aprovado em: 12/11/2020

Revista Devir Educação, Lavras, vol.4, n.2, p.431-444 jul./dez., 2020. 